\title{
Associação de imunoestimulante com anti-helmíntico no tratamento da verminose em ovinos
}

\author{
Association of immunostimulant with anthelmintic on the treatment of sheep verminosis
}

\author{
Maria de Fátima Monteiro Martins ${ }^{\mathrm{I}}$ Maurício GarciaI Sabrina Caruso Chate ${ }^{\mathrm{II}}$ \\ Fabrízia Aparecida Tavolari ${ }^{\text {II }}$ Raffaella Bertoni Cavalcanti Teixeira ${ }^{\text {II }}$ Luis Roberto Mertens Júnior ${ }^{\text {II }}$ \\ Marilene Machado Silva ${ }^{\text {II }}$ Monika Scheibel ${ }^{I I}$ Lúcia Jamli Abel $^{I^{*}}$
}

\section{RESUMO}

\begin{abstract}
Este estudo teve como objetivo verificar a eficiência do uso de imunoestimulante associado a anti-helmíntico no tratamento das helmintoses de ovinos. Os animais do grupo I $(n=29)$ receberam o anti-helmíntico albendazole $\left(11 \mathrm{mg} \mathrm{kg}^{-1}\right)$ em administração única e o imunoestimulante composto de Propionibacterium granulosum (16ug $\mathrm{kg}^{-1}$ ) e lipopolissacarídeo (LPS) de Escherichia coli $\left(1,2 \mathrm{ug} \mathrm{kg}^{-1}\right)$ em duas doses com intervalo de 48 horas e os animais do grupo II $(n=29)$ receberam o anti-helmíntico albendazole $\left(11 \mathrm{mg} \mathrm{kg}^{-1}\right)$. Amostras foram colhidas semanalmente durante 28 dias para a realização da contagem total e diferencial de leucócitos, hematócrito e contagem de ovos por grama de fezes (OPG). Os animais que receberam imunoestimulante associado a antihelmíntico apresentaram aumento significativo dos valores de eosinófilos e linfócitos $(P<0,05)$ em relação aos animais que receberam somente anti-helmíntico. Na contagem de ovos por grama de fezes (OPG), não foram observadas diferenças significativas entre os grupos $(P>0,05)$. Com base nesses resultados, pode-se concluir que imunoestimulantes podem ser utilizados associados a anti-helmínticos como alternativa terapêutica no tratamento das helmintíases em ovinos, uma vez que promovem a ativação da resposta imune com participação de células e mediadores importantes para a eliminação de helmintos em ovinos.
\end{abstract}

Palavras-chave: helmintos, albendazole, LPS, Propionibacterium granulosum, hemograma.

\section{ABSTRACT}

This study aimed to verify the effectiveness of the immunostimulant combined with anthelmintic on the helminthiasis treatment in sheep. The animals of group I $(n=29)$ received the anthelmintic albendazole $\left(11 \mathrm{mg} \mathrm{kg}^{-1}\right)$ in a single administration and the immunostimulant composed with Propionibacterium granulosum (16ug $\mathrm{kg}^{-1}$ ) and lypopolysaccharide (LPS) of Escherichia coli $\left(1,2 \mathrm{ug} \mathrm{kg}^{-1}\right)$ into two doses every 48 hours and the animals from group II $(n=29)$ received anthelmintic albendazole $\left(11 \mathrm{mg}^{-1}\right)$. Samples were collected weekly during 28 days, to carry out the total and differential count of leukocytes, hematocrit and the eggs count per gram of feces (EPG). The animals that received immunostimulant combined with anthelmintic showed significantly increases of eosinophils and lymphocytes $(P<0.05)$ compared to animals that only received the anthelmintic. In eggs count per gram of feces (EPG), there were no significant differences between groups $(P>0.05)$. Based on these results it was concluded that immunostimulants can be used when combined with anthelminthic as an alternative therapy for the treatment of helminthiasis in sheep, since they promote the activation of immune response with participation of cells and mediators important for the removal of helminths in sheep.

Key words: helminths, albendazole, LPS, Propionibacterium granulosum, blood cell count.

\section{INTRODUÇÃO}

As infecções por nematoides gastrintestinais em ruminantes causam consideráveis prejuízos econômicos por todo o mundo e, no Brasil, representam um importante problema sanitário (AMARANTE et al., 2004; RAMOS et al., 2004). Na ovinocultura, o uso indiscriminado de anti-helmínticos, aliada a práticas inadequadas de manejo, tem promovido crescente aumento de parasitas resistentes, retratando

'Programa de Pós-graduação em Medicina Veterinária, Área de Concentração Imunopatologia, Universidade Paulista (UNIP), 04026-002, São Paulo, SP, Brasil. E mail: luciaabel@uol.com.br.*Autor para correspondência.

"Hospital Veterinário, UNIP, São Paulo, SP, Brasil. 
a real necessidade da elaboração de novas alternativas terapêuticas (VIEIRA\& CAVALCANTE, 1999).

Alguns trabalhos mostraram que, em ovinos, a resistência aos nematoides gastrintestinais como Trichostrongylus colubriformis e Haemonchus contortus é mediada por mecanismos imunológicos (GILL, 1991). De uma maneira geral, a resposta imune aos helmintos é caracterizada por uma resposta do tipo Th2 com a participação de linfócitos TCD4+, produtores de citocinas como IL-4, IL-5 e IL-13, as quais promovem a ativação de eosinófilos e mastócitos, que, quando estimulados, liberam grânulos tóxicos e ativam linfócitos B para a produção de anticorpos IgE (ABBAS et al., 2005). Em ovinos, a presença de IL-5 e anticorpos IgE no tecido abomasal são importantes para a ativação de eosinófilos (RAINBIRD et al., 1998; BALIC, et al., 2000), leucócitos globulares intraepiteliais e mastócitos na mucosa para a eliminação das larvas L3 de $\boldsymbol{H}$. contortus (SHAW et al., 1998).

Os imunoestimulantes são substâncias capazes de estimular a resposta imune inespecífica e podem ser utilizados com o objetivo de aumentar a resistência de animais expostos ao risco de infecções (QUINN, 1990; PELL, 1995). Imunoestimulantes a base de lipopolissacarídeo (LPS) e Propionibacterium granulosum, estimulam a resposta imune em animais e humanos (KO et al., 1981; PANG et al., 1994) e, em condições de imunossupressão, são capazes de promover a ativação de linfócitos B (GALLEGOOLIVELLA et al., 1998) e diminuir os efeitos adversos como na doença de Aujeszky e peste suína clássica (MAKOWSKA-DANIEL et al., 1992). A condição imune dos animais com verminose pode estar associada à severidade da doença. GARCIA et al. (2004) mostraram que ovinos tratados com ciclofosfamida submetidos à imunossupressão apresentaram maiores contagens de ovos por grama de fezes e diminuição de valores de proteínas séricas (CHATE, 2005).

Recentemente, trabalho do grupo mostrou que o tratamento de ovinos com imunoestimulante a base de Lipopolissacarídeo (LPS) e Propionibacterium acnes, promoveu aumento da resposta imune do tipo Th2, com ativação de eosinófilos, linfócitos, aumento de IL-5 e produção de IgE, resultando na diminuição significativa do OPG em modelo de verminose experimental (ABEL et al., 2009). Os eosinófilos, quando ativados por IgE, liberam grânulos tóxicos como a proteína básica principal que destroem o parasita (ABBAS et al., 2005; TIZARD, 2002), sendo controlados pela ação de mediadores como a IL-5. Tendo em vista que o uso de imunoestimulantes foi eficaz na eliminação de parasitas através da ativação de células e mediadores da resposta imune do tipo Th2, aliada a necessidade de alternativas terapêuticas para o tratamento da verminose, este trabalho teve como objetivo verificar o efeito da associação de imunoestimulante a base de LPS e $\boldsymbol{P}$. granulosum com o anti-helmíntico albendazole no tratamento da verminose em ovinos naturalmente infectados.

\section{MATERIAL E MÉTODOS}

Foram utilizados 58 ovinos sem raça definida, fêmeas, adultas, idade média de 12 meses e peso médio de $40 \mathrm{~kg}$ de peso vivo, naturalmente contaminados por helmintos, provenientes de uma propriedade localizada na cidade de Itanhaém, litoral paulista. Os animais foram mantidos em baias em regime semi-intensivo, alimentados com capim picado e ração comercial. Na composição dos grupos, foram realizadas contagens de ovos por grama de fezes (OPG) anterior ao tratamento. Pela média dessas contagens, os animais foram divididos em dois grupos experimentais com 29 animais cada grupo de forma que as médias do OPG fossem semelhantes: os animais que receberam imunoestimulante Inmodulem Calier a base de Propionibacterium granulosum (16ug kg ${ }^{-1}$ e LPS de Escherichia coli $\left(1,2 \mathrm{ug} \mathrm{kg}^{-1}\right)$, em duas doses por via intramuscular com intervalo de 48 horas e uma dose do anti-helmíntico albendazole $\left(11 \mathrm{mg} \mathrm{kg}^{-1}\right)$ (Duothal, Minerthal) por via oral foram denominados grupo I, e os animais que receberam o anti-helmíntico albendazole $\left(11 \mathrm{mg} \mathrm{kg}^{-1}\right)$, grupo II.

As colheitas de sangue e fezes foram realizadas semanalmente durante 28 dias, no dia do tratamento (dia 0 ) e nos dias 7, 14, 21 e 28 após a administração. Amostras de sangue foram obtidas por venopunção jugular em frascos a vácuo com EDTA, e o hemograma processado pelo método do hemocitômetro, de acordo com HEWITT, 1984, sendo a contagem diferencial de leucócitos realizada em extensão sanguínea corada por panótico rápido (Instant-Prov, Newprov) (KERR, 2003) e o hematócrito determinado por microcentrifugação, de acordo com o método descrito por SCHALM et al. (1975). Amostras de fezes foram coletadas diretamente da ampola retal com utilização de sacos plásticos devidamente identificados para realização do OPG, segundo a técnica de GORDON \& WHITLOCK (1939), e para coprocultura (ROBERTS \& O'SULLIVAN, 1950).

A eficácia do tratamento foi avaliada através dos parâmetros hematológicos e contagem de ovos por grama de fezes (OPG). A diferença entre as médias dos valores encontrados nos animais do grupo I e II foi estimada pelo teste não paramétrico (Mann-Withney Rank Sum,programa Graph Pad Prism Instat ${ }^{\mathrm{tm}}$ ). Valores de $\mathrm{P}<0,05$ foram considerados significativos. 


\section{RESULTADOS E DISCUSSÃO}

Os animais do grupo I, tratados com imunoestimulante e anti-helmíntico, apresentaram aumento significativo dos valores eosinófilos e linfócitos $(\mathrm{P}<0,05)$ em relação aos animais do grupo II, conforme mostra tabela 1 . O aumento desses valores verificado nos animais do grupo I ocorreu pela ação do imunoestimulante, visto que animais tratados com compostos a base de LPS e $\boldsymbol{P}$. granulosum apresentaram neutrofilia, eosinofilia e um aumento da resposta de linfócitos $\mathrm{T}$ e B, com alterações importantes na atividade da medula óssea (MENDOZA et al., 2000). Esses resultados corroboram os achados de ABEL et al. (2009), os quais evidenciaram aumento significativo no número de eosinófilos e correlação negativa entre eosinófilos circulantes e OPG nos animais do grupo tratado com o imunostimulante a base de LPS e Propionibacterium acnes. Os eosinófilos são células importantes na eliminação dos helmintos e, quando ativados por IgE, liberam grânulos tóxicos como a proteína básica principal que destroem o parasita (ABBAS et al., 2005; TIZARD, 2002), sendo controlada pela ação de mediadores como a IL-5 (MEEUSEN et al., 2005; PERNTHANER et al., 2005). Nos animais do grupo
II, observou-se aumento de leucócitos a partir do 14을 dia após o tratamento, porém sem diferença estatística em relação aos animais do grupo $\mathrm{I}(\mathrm{P}>0,05)$. Em relação à contagem de neutrófilos e monócitos, não foi observada diferença estatística entre os grupos I e II. Após uma semana de tratamento (dia 7), observou-se queda significativa do OPG nos animais dos grupos I e II, possivelmente pela ação do anti-helmíntico e imunostimultante (Tabela 2), coincidindo com aumento dos índices do hematócrito (Tabela 1). Entretanto, não se observou diferença significativa na contagem de ovos por grama de fezes (OPG) entre os grupos I e II ( $\mathrm{P}>0,05)$, devido à alta variabilidade nas contagens, não sendo o OPG representativo do número exato de nematoides que parasitam o trato digestório do animal.

Neste estudo, verificou-se que $98 \%$ das larvas desenvolvidas na coprocultura pertenciam ao gênero Haemonchus e 2\% pertenciam ao gênero Strongyloides e Trichostrongylus. Além de patogênicos, os helmintos do gênero Haemonchus são mais prevalentes nos rebanhos com relatos de resistência anti-helmíntica (MELO et al., 2003).

O efeito do imunoestimulante composto de uma suspensão de Propionibacterium acnes na modulação da resposta imune foi demonstrado por

Tabela 1 - Valores percentuais médios e desvio padrão dos ovinos do grupo I- tratados com $\boldsymbol{P}$. granulosum (16ug kg ${ }^{-1}$ ) e LPS de $\boldsymbol{E}$. coli $\left(1,2 \mathrm{ug} \mathrm{kg}^{-1}\right)$, (Inmodulen ${ }^{\circledR}$ Calier) - e ovinos do grupo II -tratados com o anti-helmíntico albendazole $\left(11 \mathrm{mg} \mathrm{kg}^{-1}\right)$.

\begin{tabular}{|c|c|c|c|c|c|c|}
\hline Parâmetros & Grupo & Dia 0 & Dia 7 & Dia 14 & Dia 21 & Dia 28 \\
\hline \multirow[t]{2}{*}{$\begin{array}{l}\text { Hematócrito } \\
(27 \% \text { a } 45 \%)\end{array}$} & I & $(25,2 \pm 4,5)$ & $(25,1 \pm 3,6)$ & $(27,6 \pm 3,5)$ & $(27,7 \pm 3,6)$ & $(27,4 \pm 4,13)$ \\
\hline & II & $(25,5 \pm 5,7)$ & $(24,6 \pm 4,2)$ & $(26,1 \pm 4,2)$ & $(27,2 \pm 4,0)$ & $(27,8 \pm 4,0)$ \\
\hline \multirow[t]{2}{*}{$\begin{array}{l}\text { Leucócitos } \\
\left(4.000 \text { a } 12.000 \mathrm{uL}^{-1}\right)\end{array}$} & I & $(8.476 \pm 2457)$ & $(8.190 \pm 2128)$ & $(8.341 \pm 2211)$ & $(8.855 \pm 2063)$ & $(9.192 \pm 2618)$ \\
\hline & II & $(9.614 \pm 2714)$ & $(8.645 \pm 2207)$ & $(8.166 \pm 2084)$ & $(8.331 \pm 1929)$ & $(8.648 \pm 2899)$ \\
\hline \multirow[t]{2}{*}{$\begin{array}{l}\text { Neutrófilos } \\
\left(700 \text { a } 6.000 \mathrm{uL}^{-1}\right)\end{array}$} & I & $(3668 \pm 1163)$ & $(4040 \pm 1708)$ & $(3823 \pm 1881)$ & $(3909 \pm 1507)$ & $(3637 \pm 1580)$ \\
\hline & II & $(4400 \pm 1609)$ & $(4688 \pm 2264)$ & $(3715 \pm 1659)$ & $(3770 \pm 1762)$ & $(3810 \pm 2101)$ \\
\hline \multirow{2}{*}{$\begin{array}{l}\text { Linfócitos } \\
\left(2.000 \text { a } 9.000 \mathrm{uL}^{-1}\right)\end{array}$} & I & $(3.808 \pm 1333)$ & $(3.524 \pm 1294)$ & $(4.442 \pm 1363)$ & $(4.932 \pm 1481)^{\mathrm{a}}$ & $(4.887 \pm 1600)^{\mathrm{a}}$ \\
\hline & II & $(4146 \pm 1248)$ & $(3350 \pm 1071)$ & $(4045 \pm 1368)$ & $(3583 \pm 1034) b$ & $(3534 \pm 1857) b$ \\
\hline \multirow[t]{2}{*}{$\begin{array}{l}\text { Eosinófilos } \\
\left(0 \text { a1000uL }{ }^{-1}\right)\end{array}$} & I & $(501 \pm 365)$ & $(309 \pm 222)$ & $(206 \pm 333)$ & $(290 \pm 266)^{\mathrm{a}}$ & $(555 \pm 424)^{\mathrm{a}}$ \\
\hline & II & $(573 \pm 486)$ & $(344 \pm 338)$ & $(118 \pm 197)$ & $(172 \pm 183) b$ & $(359 \pm 323) b$ \\
\hline \multirow[t]{2}{*}{$\begin{array}{l}\text { Monócitos } \\
\left(0 \text { a } 750 \mathrm{uL}^{-1}\right)\end{array}$} & I & $(475 \pm 311)$ & $(317 \pm 305)$ & $(231 \pm 165)$ & $(228 \pm 150)$ & $(363 \pm 291)$ \\
\hline & II & $(495 \pm 379)$ & $(263 \pm 186)$ & $(288 \pm 197)$ & $(190 \pm 125)$ & $(320 \pm 307)$ \\
\hline
\end{tabular}

Médias seguidas de letras diferentes na mesma coluna indicam diferença significativa $(\mathrm{P}<0,05)$.

Ciência Rural, v.42, n.12, dez, 2012. 
Tabela 2 - Valores absolutos de OPG e valores percentuais do OPG dos ovinos do grupo I (tratados com imunoestimulante contendo $\boldsymbol{P}$. granulosum e LPS de E. coli e anti-helmíntico albendazole) e grupo II (controle, tratados somente com anti-helmíntico albendazole).

\begin{tabular}{lllll}
\hline & \multicolumn{2}{c}{ I } & \multicolumn{2}{c}{ II } \\
\hline Dia & Média & Desvio & Média & Desvio \\
0 & $2510 \mathrm{a}$ & 2382 & $4031 \mathrm{a}$ & 3216 \\
7 & $412 \mathrm{a}$ & 417 & $484 \mathrm{a}$ & 329 \\
14 & $569 \mathrm{a}$ & 482 & $581 \mathrm{a}$ & 440 \\
28 & $853 \mathrm{a}$ & 400 & $1082 \mathrm{a}$ & 599 \\
\hline
\end{tabular}

Letras iguais na mesma linha sem diferença significativa $(\mathrm{P}>0,05)$.

BRAGA et al., 2003, em que a resposta celular a um antígeno Th2 pode ser suprimida ou potencializada, dependendo do esquema de tratamento.

Outros autores já haviam observado o efeito modulador de polissacarídeos obtidos de sobrenadantes de cultura de P. acnes (DAWES et al., 1974). Assim como o extrato de $\boldsymbol{P}$. acnes, a injeção intraperitoenal do polissacarídeo de $\boldsymbol{P}$. acnes foi capaz de induzir a produção de NO (óxido nítrico) e liberação de TNF-alfa com aumento da atividade fagocítica de macrófagos peritoneais, além de ser capazes de promover resistência'a infecção (ANANIAS et al., 2007; LONGHINI et al., 2001).

Em recente trabalho, verificou-se que animais tratados com a fração polissacarídica de $\boldsymbol{P}$. acnes apresentaram aumento significativo no número de leucócitos após a administração da fração polissacarídica de $\boldsymbol{P}$ acnes, com correlação negativa significativa entre linfócitos e eosinófilos e carga parasitária (OPG). A eosinofilia aliada ao aumento dos níveis de IL-5 e IgE nos animais do grupo tratado com a fração polissacarídica de $\boldsymbol{P}$. acnes caracteriza a presença de uma resposta imune do tipo Th2 (VENTURINI et al., 2010), intimamente relacionada com mecanismos de resistência e expulsão dos vermes (GILL et al., 2000). A associação de resistência a helmintos e eosinofilia tem sido demonstrada em modelos in vitro (RAINBIRD, 1998; TEREFE etal., 2007) e in vivo (BALIC et al., 2006), sendo células importantes na eliminação de parasitas através da liberação de grânulos tóxicos.

\section{CONCLUSÃO}

Os resultados mostraram que animais tratados com anti-helmíntico associado a imunoestimulante apresentaram um aumento significativo de eosinófilos e linfócitos em relação aos animais tratados somente com anti-helmíntico. O aumento dessas células ocorreu por conta da ação do imunoestimulante, corroborando achados recentes. Observou-se diminuição do OPG em ambos os grupos após o tratamento, podendo ser utilizado como alternativa terapêutica no tratamento das helmintoses em ovinos, minimizando os efeitos de resistência aos anti-helmínticos convencionais. Estudos posteriores utilizando a contagem total de vermes em necrópsia de animais naturalmente infectados poderão elucidar a ação anti-helmíntica dessa associação.

\section{AGRADECIMENTOS}

À Fundação de Amparo a Pesquisa do Estado de São Paulo (FAPESP).

\section{COMITÊ DE ÉTICA E BIOSSEGURANÇA}

Os procedimentos envolvendo animais foram realizados de acordo com os princípios éticos de experimentação animal, sendo aprovado pelo Comitê de Ética em Experimentação Animal da Universidade Paulista (UNIP), protocolo 05/0645-3.

\section{REFERÊNCIAS}

ABBAS, A. et al. Imunologia celular e molecular. São Paulo: Revinter, 2005. 544p.

ABEL, L.C.J. et al. Adjuvant effect of LPS and killed Propionibacterium acnes on the development of experimental gastrointestinal nematode infestation in sheep. Parasite Immunology, v.31, p.604-612, 2009. Disponível em: <http:/ /onlinelibrary.wiley.com/doi/ $10.111 /$ j. 1365 3024.2009.01132.x/abstract>. Acesso em: 08 out. 2011. doi: 10.1111/j.1365-3024.2009.01132.x.

AMARANTE, A.F.T et al. Resistance of Santa Ines, Suffolk and Ile de France sheep to naturally acquired gastrointestinal nematode infections. Veterinary Parasitology, v.26, n.1-2, 91-106, 2004. Disponível em: <http://dx.doi.org/10.1016/ j.vetpar.2003.12.004>. Acesso em: 08 abr. 2012. doi: 10.1016/ j.vetpar.2003.12.004.

ANANIAS, R.Z. et al. Modulatory effect of killed Propionibacterium acnes and its purified soluble polysaccharide on peritoneal exudate cells from C57B1/6 mice: major NKT cell recruitment and increased cytotoxicity. Scandinavian Journal of Immunology, v.65, n.6, p.538-548, 2007. Disponível em: <http://onlinelibrary.wiley.com/doi/10.1111/ j.1365-3083.2007.01939.x/abstract>. Acesso em: 10 abr. 2012. doi: 10.1111/j.1365-3083.2007.01939.x.

BALIC, A. et al. Cellular profiles in the abomasal mucosa and lymph node during primary infection with $\boldsymbol{H}$. contortus in sheep. Veterinary Immunology and Immunopathology, v.75, n.12, p.109-120, 2000. Disponível em: <http://dx.doi.org/ 10.1016/S0165-2427(00)00189-6>. Acesso em: 20 mar. 2012. doi: 10.1016/S0165-2427(00)00189-6. 
BALIC, A. et al. Eosinophil interactions with $\boldsymbol{H}$. contortus larvae in the ovine gastrointestinal tract. Parasite Immunology, v.28, n.3, p.107-15, 2006. Disponível em: $<$ http://onlinelibrary.wiley.com/doi/10.1111/j.13653024.2006.00816.x/abstract>. Acesso em: 10 abr. 2011. doi: 10.1111/j.1365-3024.2006.00816.x.

BRAGA, E.G. et al. Treatment with Propionibacterium acnes modulates the late phase reaction of immediate hypersensitivity in mice. Immunology Letters, v.88, n.2, p.163-169, 2003. Disponível em: 〈http://dx.doi.org/10.1016/S0165-2478(03)00079-8>. Acesso em: 24 abr. 2011. doi: 10.1016/S0165-2478(03)00079-8.

CHATE, S. Efeito de immunossupressão no desenvolvimento da verminose em ovinos. 2005. 130f. Dissertação (Mestrado em Imunopatologia Veterinária) - Curso de Pós-graduação em Medicina Veterinária e Imunopatologia Universidade Paulista, SP.

DAWES J. et al. Properties of an antigenic polysaccharide from Corynebacterium parvum. Journal of Bacteriology, v.120, n.1, p.24-30, 1974. Disponível em: <http://jb.asm.org/ content/120/1/24.long>. Acesso em: 02 fev.2011.

GALLEGO-OLIVELLA, J. et al. Study of immunostimulating effect of IM-104 in mice. Federation of European Microbiological Societies, v.19, p.331-333, 1997. Disponível em: <http://onlinelibrary.wiley.com/doi/10.1111/ j.1574-695X.1997.tb01104.x/abstract>. Acesso em: 17 out. 2011. doi 10.1111/j.1574-695X.1997.tb01104.

GARCIA, M. et al. Diferentes doses de ciclofosfamida no sistema imune de ovinos. Ciência Rural, v.34, n.6, p.1885-1888, 2004. Disponível em: <http://www.scielo.br/scielo.php?script=sci_arttext\&pid=S010384 $782004000600033 \& \operatorname{lng}=e n \& n r m=i s o \& t \operatorname{lng}=e n>$. Acesso em: $17 \mathrm{abr}$. 2011. doi: 10.1590/S0103-84782004000600033.

GILL, H.S. Genetic control of acquired resistance to haemonchosis in Merino lambs. Parasite Immunology, v.13, p.617, 1991. Disponível em: 〈http://onlinelibrary.wiley.com〉. Acesso em: 17 out. 2011. doi: 10.1111/j.13653024.1991.tb00557.

GILL, H.S. et al. Induction de T helper 1 and $\mathrm{T}$ helper 2 immune responses during Haemonchus contortus infection in sheep. Immunology, v.99, n.3, p.458-463, 2000. Disponível em: <http://onlinelibrary.wiley.com/doi/ $10.1046 /$ j.13652567.2000.00974.x/abstract>. Acesso em: 10 abr. 2012. doi: 10.1046/j.1365-2567.2000.00974.x.

GORDON, H.M.; WITHLOCK, H.V. A new technique for counting nematode eggs in sheep faeces. Journal of Council of Science and Industry Research in Australia, v.12. p.5052,1939

HEWITT, S.G. Manual of veterinary investigation, laboratory techniques. 3.ed. London: Her Majesty's Stationery Office, 1984. V.2, p.72-100.

KERR M.G. Exames laboratoriais em medicina veterinária. Bioquímica clínica e hematologia. 2.ed. São Paulo: Roca, 2003. 436p.

KO, H.L et al. Comparative study on the immunostimulatory potency of different Propionebacterium strains. Medical Microbiology Immunology, v.170, p.1-9, 1981. Disponível em: <http://www.springerlink.com/content/76625453452n0360/>. Acesso em: 17 out. 2011. doi: 10.1007/BF02123791.
LONGHINI A.L.F. et al. Soluble polyssacharide from Propionibacterium acnes with biological effects. In: INTERNATIONAL CONGRESS OF IMMUNOLOGY, 11., 2001, Estocolmo, Suécia. Scandinavian Journal of Immunology, v.54, Suppl., p.90, 2001.

MAKOWSKA-DANIEL, I. et al. Adjuvant properties of $\boldsymbol{P}$. avidum $\mathrm{kp}-40$ in vaccination against endemic viral and bacterial infections swine immunized with live atenuated Aujeskys disease virus vaccine and experimental infected with virulent viruses. Zentralbl Bakteriology, v.277, p.529-537, 1992. Disponível em: 〈http://www.ncbi.nlm.nih.gov/pubmed/1338942〉. Acesso em: 17 out.2011. doi: PMID.1338942.

MEEUSEN, E.N. et al. Cells cytokines and other molecules associated with rejection of gastrointestinal nematode parasites. Veterinary Immunology Immunopathology, v.108, p.121125, 2005. Disponível em: <http://www.sciencedirect.com/ science/article/pii/S0165242705002072>. Acesso em: 17 out. 2011. doi: 10.1016/j.vetimm.2005.07.002.

MELO, A.C.F.L. et al. Nematódeos resistentes a anti-helmínticos em rebanhos de ovinos e caprinos no estado do Ceará, Brasil. Ciência Rural, v.33, n.2, p.339-344, 2003. Disponível em: <http:/ /www.scielo.br/scielo.php?script=sci_abstract\&pid=S01038478200 $3000200024 \& \operatorname{lng}=$ en\&nrm=iso\&tlng=en>. Acesso em: 17 out. 2011. doi: 10.1590/S0103-84782003000200024.

MENDOZA, G.J.P. et al. In vitro and in vivo effects of an immunomodulator composed of $\boldsymbol{E}$. coli LPS and P. granulosuminativated cells in pigs. Journal of Veterinary Medicine, v.47, p.619-627, 2000. Disponível em: 〈http://onlinelibrary.wiley.com〉. Acesso em: 11 out. 2011. doi:10.1046/j.1439-0450.2000.00395.x/ abstract.

PANG, G. et. al. GMSF, IL-1 alfa, IL-1 beta,IL-6, IL-8, IL-10, ICAM-1 and V-CAM-1 gene expression and cytokine production in human duodenal fibroblasts stimulated with lipopolysaccharide IL-1 alfa e TNF-alfa. Clinical Experimental Immunology, v.96, p.437-443, 1994. Disponível em: <http:// www.ncbi.nlm.nih.gov/pmc/articles/PMC1534573/ ?tool=pubmed>. Acesso em: 17 out 2011. doi: 10.1111/j.13652249.1994.tb06048.x.

PELL, J.M. Principles of immunomodulation. Livestock Production Science, v.42, p.123-133, 1995. Disponível em: <http://www.sciencedirect.com/science/article/pii/ 030162269500013B>. Acesso em: 17 out. 2011. doi: 10.1016/ 0301-6226(95)00013-B.

PERNTHANER A; et al. Total and nematode-specific IgE response in intestinal lymp of genetically resistant and susceptible sheep during infection with $T$. columbriformis. Veterinary Immunology Immunopathology, v.104, p.6980, 2005. Disponível em: <http://www.sciencedirect.com/ science/article/pii/S0165242704003113>. Acesso em: 17 out. 2011. doi: 10.1016/j.vetimm.2004.10.008.

QUINN, P.J. Mechanisms of action of some immunomodulators used in veterinary medicine. Advances in Veterinary Science and Comparative Medicine, v.35, p.43-99, 1990. Disponível em: $<\mathrm{h} \mathrm{t} \mathrm{t} \mathrm{p} \mathrm{:} \mathrm{/} \mathrm{/} \mathrm{w} \mathrm{w} \mathrm{w.} \mathrm{n} \mathrm{c} \mathrm{b} \mathrm{i.n} 1 \mathrm{~m}$. n i h.g o v / pubmed?term=QUINN\%2C\%20P.\%20J.\%20Mechan is ms $\% 20$ of $\% 20$ action $\% 20$ of $\% 20$ some $\% 20 \mathrm{im} \mathrm{m}$ unomodulators $\% 20$ used $\% 20 \mathrm{in} \% 20$ veterinary $\% 20 \mathrm{~m}$ edicine. $\% 20 \mathrm{Advances} \% 20 \mathrm{in} \% 20$ Veterinary $\% 20$ Science $\%$ 
20and $\% 20$ Comparative $\% 20$ Medicine $\% 20$ v. 35\%2C\%20p.4399\%2C\%201990>. Acesso em: 17 out. 2011. doi: PMID: 2284999.

RAINBIRD, M.A et al. Eosinophil-mediated killing of $\boldsymbol{H}$. contortus larvae: effect of eosinophil activation and role of antibody, complement and IL-5. Parasite Immunology, v.20, n.2, p.93-103, 1998. Disponível em: <http:// onlinelibrary.wiley.com/doi/10.1046/j.1365-3>. Acceso em: 12 fev. 2012. doi:10.1046/j.1365-3024.1998.00132.x.

RAMOS, C.I. et al. Epidemiologia das helmintoses gastrintestinais de ovinos no Planalto Catarinense. Ciência Rural, v.34, p.1889-1895, 2004. Disponível em: <http:// www.scielo.br/scielo.php? script $=$ sci_abstract\&pid $=$ S010384782004000600034\&lng=en\&nrm=iso\&tlng=en >. Acesso em: 17 out. 2011. doi: 10.1590/S010384782004000600034 .

ROBERTS, F.H.S.; O'SULLIVAN, J.P. Methods for egg counts and larval cultures for strongyles infesting the gastrointestinal tract of cattle. Australian Journal of Agriculture Research, v.1, p.99-102, 1950.

SCHALM, O.W. et al. Veterinary hematology. 3.ed. Philadelphia: Lea e Febiger, 1975. 807p.

SHAW, R.J. et al. Serum IgE responses during primary and challenge infections of sheep with Trichostrongylus colubriformis. International Journal of Parasitology, v.28, p.293-302,1998. Disponível em: <http://dx.doi.org/10.1016/ S0020-7519(97)00164-1>. Acesso em: 14 abr. 2012. doi: 10.1016/S0020-7519(97)00164-1.

TEREFE, G. et al. Immune response to Haemonchus contortus infection in susceptible (INRA 401) and resistant (Barbados Black Belly) breeds of lambs. Parasite Immunology, v.29, p.415424, 2007. Disponível em: <http://onlinelibrary.wiley.com/doi/ 10.1111/j.13653024.2007.00958.x/abstract>. Acesso em: 17 out. 2011. doi: 10.1111/j.1365-3024.2007.00958.x.

TIZARD, I.R. Imunologia veterinária. 6.ed. São Paulo: Roca, 2002. 532p.

VENTURINI, T.F. et al. Modulatory effects of the soluble polysaccharide fraction of Proprionibacterium acnes on helminthiasis in sheep. In: INTERNATIONAL CONGRESS OF IMMUNOLOGY, 114., 2010, Kobe Japan. International Immunology, v.22, suppl I, p.158, 2010.

VIEIRA, L.S.; CAVALCANTE, A.C.R. Anthelmintic resistance in goat herds in the State of Ceará. Pesquisa Veterinária Brasileira, v.19, p.99-103, 1999. Disponível em: <http:// www.scielo.br/scielo.php? script =sci_abstract \&p $\mathrm{id}=\mathrm{S} 0100736 \mathrm{X} 1999000300002 \& \operatorname{lng}=\mathrm{en} \& \mathrm{nrm}=\mathrm{i}$ so\&tlng $=\mathrm{en}>$. Acesso em: 17 out. 2011. doi: 10.1590/S0100736X1999000300002. 